\title{
The association of systemic lupus erythematosus and myasthenia gravis
}

\author{
G. Vaiopoulos', P.P. Sfikakis ${ }^{1,2}$, V. Kapsimali ${ }^{1}$, K. Boki ${ }^{1}$, P. Panayiotidis ${ }^{1}$, \\ A. Aessopos ${ }^{1}$, G.C. Tsokos ${ }^{2}$ and P. Kaklamanis ${ }^{1}$ \\ 'First Department of Internal Medicine, Laikon General Hospital, Athens University Medical School, \\ Athens, Greece and ${ }^{2}$ Department of Medicine, Uniformed Services University of the Health Sciences, \\ Bethesda, MD, USA
}

\begin{abstract}
Summary: Two women with the rare association of systemic lupus erythematosus (SLE) and myasthenia gravis (MG) are reported. The first patient developed SLE (arthritis, severe thrombocytopenia, and high titres of anti-DNA antibodies) 6 years following successful therapeutic thymectomy for MG. The second patient developed SLE (oral ulcers, arthritis, serositis, leukopenia, high titres of anti-DNA and anti-nuclear antibodies) 4 years prior to the clinical and serological onset of MG. Lymphocyte subsets and in vitro proliferative responses of peripheral blood mononuclear cells to mitogens were normal in both patients. A review of the literature revealed 26 additional patients with definite SLE coexisting with MG. Besides the theoretical interest of this association, the differential diagnosis of fatigue in patients with SLE should always include the possibility of MG.
\end{abstract}

\section{Introduction}

Systemic lupus erythematosus (SLE) and myasthenia gravis (MG) are autoimmune disorders in which genetic, environmental and hormonal as well as immunological factors have been implicated..$^{1-3}$ The coexistence of SLE and MG has occasionally been reported but there has been no controlled epidemiological study to prove a real association between these two diseases. Two new cases of SLE and MG are presented and discussed here. In addition, we have reviewed all case reports since 1954 in the English and French literature meeting the 1982 American College of Rheumatology (ACR) criteria ${ }^{4}$, and coexisting with MG. Whether the association represents an autoimmune overlap or manifestations of the same disease is discussed.

\section{Case 1}

A 37 year old woman with a 2 year history of intermittent polyarthritis affecting hands and knees, alopecia and thrombocytopenia was admitted for evaluation. Seventeen years prior to admission the patient developed progressive proximal muscle weakness during her first pregnancy. One week after delivery she noted bilateral eyelid ptosis

Correspondence: P. Kaklamanis, M.D., 16 Anaperon Polemou Str., Athens, 115 21, Greece.

Accepted: 21 February 1994 and difficulty in swallowing. MG was suspected and this diagnosis was confirmed by a positive tensilon test and typical electromyographic findings. Prostigmine and corticosteroids were started and continued for 10 years. At that time thymectomy was performed; histology revealed marked hyperplasia of thymic germinal centres. Thymectomy resulted in complete remission of myasthenic symptoms. On examination the patient had a low grade fever up to $37.8^{\circ} \mathrm{C}$, arthritis involving the wrists and knees, alopecia and purpuric lesions on the lower extremities. The rest of the clinical examination was unremarkable. Laboratory data include: erythrocyte sedimentation rate (ESR) $48 \mathrm{~mm} / 1$ hour, haemoglobin $12 \mathrm{~g} / \mathrm{dl}$, white blood cell count (WBC) $6.5 \times 10^{9} / 1$, with normal differential, platelet count $10 \times 10^{9} / 1$. Urinalysis, liver and renal function tests, and serum levels of creatine kinase (CK) and aldolase were within the normal range. An indirect Coomb's test was positive. Serum anti-nuclear antibodies (ANA) (indirect immunofluorescence) was positive at a titre of 1:640 with a homogeneous pattern. AntiDNA antibodies were found to be $55 \mathrm{U} / \mathrm{ml}$ (normal $<7 \mathrm{U} / \mathrm{ml}$ ). Anti-RNP and anti-platelet antibodies were also present in the serum. Antibodies to acetylcholine receptors (anti-R-ach) were not detected. Serum complement level (total, C3 and C4) was normal.

The diagnosis of SLE was made (arthritis, thrombocytopenia, high titres of anti-DNA and 
ANA,${ }^{4}$ and treatment with $60 \mathrm{mg}$ of prednisone per day was instituted, with a dramatic clinical response. The dose of prednisone was gradually tapered; while the patient was on $5 \mathrm{mg}$ daily she had a flare of purpura and arthritis, and was treated with an increased dose of prednisone and the addition of danazol. Since then she has been on $5-10 \mathrm{mg}$ of prednisone and $200 \mathrm{mg}$ of danazol and appears to be free of symptoms.

\section{Case 2}

A 22 year old woman was admitted to the hospital for evaluation of proximal muscle weakness and intermittent diplopia. For the last 4 years she had suffered from arthritis involving the small joints of both hands as well as from recurrent oral ulcers. ANA were present $(1: 1,280)$ in several tests. For the last 2 years she was on oral contraceptives for irregular menses. Physical examination revealed arthritis of the hands, muscle tenderness and proximal muscle weakness. A tensilon test was performed and it was positive. Serum anti-R-ach antibodies were present at a titre of $334 \mathrm{nmol} / \mathrm{l}$ (normal values $<0.5 \mathrm{nmol} / \mathrm{l}$ ). A computed tomograpic (CT) scan of the chest was negative for thymoma. An echocardiogram showed a small amount of pericardial fluid. Laboratory data include: ESR $60 \mathrm{~mm} / 1$ hour, haemoglobin $14 \mathrm{~g} / \mathrm{dl}$, WBC $3.2 \times 10^{9} / 1$ (60\% lymphocytes) and normal platelet count. CK, aldolase, and liver and renal function tests were within the normal range. ANA test was positive at 1:1,280 with speckled and homogeneous patterns. Anti-RNP and anti-DNA antibodies $(25 \mathrm{U} / \mathrm{ml})$ were also present in the serum. A diagnosis of SLE (6 ACR criteria: oral ulcers, arthritis, serositis, leukopenia, high titres of anti-DNA and ANA), as well as the diagnosis of MG, were made.

Treatment with pyridostigmine bromide and $60 \mathrm{mg}$ of prednisone daily was started. An immediate improvement of her symptoms was noted. However, when the dose of prednisone was tapered to $15 \mathrm{mg}$ the patient relapsed and $100 \mathrm{mg}$ of azathioprine were then added. At the present time both disorders are in clinical remission. A decision for thymectomy has not been made so far.

\section{Lymphocyte subsets and in vitro proliferative responses to mitogens}

The numbers of total B cells $\left(\mathrm{CD} 22^{+}\right)$, total T cells $\left(\mathrm{CD}^{+}, \mathrm{CD}^{+}\right)$, T-helper $\left(\mathrm{CD}^{+}\right)$, $\mathrm{T}$-suppressor $\left(\mathrm{CD8}^{+}\right)$, NK cells $\left(\mathrm{CDI6}^{+}\right)$and activated mononuclear cells $\left(\mathrm{CD} 25^{+}\right)$, in the peripheral blood of both patients were measured using the appropriate monoclonal antibodies (Becton Dickinson, Moun- tain View, CA) and standard immunofluorescence. Peripheral blood mononuclear cell (PBMC) proliferation assays were performed, using phytohaemagglutinin (PHA) (Wellcome, Beckenham, UK) and monoclonal anti-CD3 antibodies (OKT3) (Ortho, Raritam, NJ) in optimal and suboptimal concentrations, as previously described. ${ }^{5}$

All lymphocyte subsets and ratios in both patients were within the normal limits. The in vitro proliferative responses of both patients PBMC to PHA and to anti-CD3 stimulation were also within the ranges of responses observed in 12 healthy persons, that have been studied under exactly the same experimental conditions, published elsewhere. ${ }^{5}$ It should be noted that steroid treatment was discontinued 24 hours prior to these studies; lymphocyte subsets determination and in vitro PBMC proliferative studies in other reports (reviewed in reference 2), of cellular immunity in patients with SLE receiving steroids, are always performed after a period of $18-24$ hours of treatment.

\section{Discussion}

Myasthenia gravis is a chronic, organ-specific autoimmune disease in which anti- $R$-ach autoantibodies are considered responsible for muscle weakness. MG has a special predilection for cranial muscles, varies in severity and is partially relieved by cholinergic drugs. In contrast, SLE is a systemic autoimmune disease that affects multiple organs and is characterized by numerous circulating autoantibodies including anti-DNA, anti-RNPs, anti-lymphocyte and anti-cytoskeletal protein. ${ }^{1-3}$

Two women with well-documented SLE and MG are described. In the first case MG was diagnosed at the age of 20 , thymectomy was performed at the age of 30 and 7 years later the diagnosis of SLE according to the ACR criteria ${ }^{4}$ was made. In the second case the diagnosis of MG was made 4 years following the diagnosis of SLE. While the first patient did not have any clinical or serological evidence of MG when SLE was diagnosed, the second patient had both diseases occurring simultaneously. The latter patient had a high titre of serum anti-R-ach antibodies, together with anti-RNP and anti-DNA antibodies, probably as a result of polyclonal B cell activation. Although contraceptives are involved in the development of drug-induced lupus, ${ }^{6}$ SLE symptoms in this case preceded the administration of contraceptives.

Despite the presence of multiple circulating autoantibodies, the cellular immunity profile in both patients studied was not abnormal. The numbers of peripheral $\mathrm{T}$ and $\mathrm{B}$ lymphocytes, and $\mathrm{T}$ cell subsets have been found normal in the majority of SLE patients. ${ }^{2}$ Such normal findings have been 
reported in patients with MG as well. ${ }^{3}$ Proliferative responses of peripheral blood mononuclear cells to PHA have been reported as decreased or normal in SLE patients, and normal in MG patients, ${ }^{1-3}$ while in the majority of SLE patients the anti-CD3induced T-cell proliferation is normal. ${ }^{7}$ It should be noted that our patients were under treatment when these determinations were performed.

Patients with coexisting SLE and MG have been reported in the literature, although the majority of the patients did not fulfil the ACR established criteria for the diagnosis of SLE. In reviewing the English and French literature we have found 26 more cases of MG coexisting with well-documented SLE. The diagnosis of MG preceded that of SLE in half of the patients ${ }^{8-14}$ (Table I), while SLE preceded the development of MG in the other half $^{8,12.15-19}$ (Table II). Tweny-six of 28 cases were women; the age of onset is the second or third decade in the majority of the cases. The various

Table I Patients with systemic lupus erythematosus (SLE) (fulfilling at least four of the ACR criteria) following myasthenia gravis (MG), including those who developed SLE after thymectomy, reported since 1954

\begin{tabular}{|c|c|c|c|c|c|}
\hline Sex & $\begin{array}{l}\text { Age at } \\
\text { MG onset } \\
\text { (years) }\end{array}$ & $\begin{array}{c}\text { Age at } \\
\text { thymectomy } \\
\text { (years) }\end{array}$ & $\begin{array}{l}\text { Age at } \\
\text { SLE } \\
\text { onset } \\
\text { (years) }\end{array}$ & $\begin{array}{c}A C R \text { diagnostic } \\
\text { criteria for } \\
S L E^{*}\end{array}$ & $\begin{array}{c}\text { Author (first) } \\
\text { (reference) }\end{array}$ \\
\hline $\mathbf{F}$ & 18 & - & 19 & $1,5,7,10$ & Denney (in 8) \\
\hline $\mathbf{F}$ & 11 & 11 & 15 & $5,6,9,10$ & Alarcon-Segovia (in 8) \\
\hline $\mathbf{M}$ & 30 & - & 50 & $1,5,6,10,11$ & Goldin (in 8) \\
\hline $\mathbf{F}$ & 11 & 11 & 15 & $1,5,6,9,10,11$ & Gelbraith (in 8) \\
\hline $\mathbf{F}$ & 30 & - & 32 & $5,7,9,10,11$ & Schoenen (in 8) \\
\hline $\mathbf{F}$ & 22 & 23 & 24 & $5,7,10,11$ & Aarli (in 8) \\
\hline $\mathrm{F}$ & 19 & 20 & 29 & $6,9,10,11$ & Kennes (in 8) \\
\hline $\mathbf{F}$ & 38 & 49 & 49 & $5,7,9,10,11$ & Mizon (8) \\
\hline $\mathbf{F}$ & 40 & 47 & 48 & $5,6,9,10,11$ & Abbruzzese (9) \\
\hline $\mathbf{M}$ & 18 & 18 & 21 & $7,9,10,11$ & Calabrese (10) \\
\hline $\mathbf{F}$ & 29 & 34 & 39 & $2,5,7,10,11$ & Le Loet (11) \\
\hline $\mathbf{F}$ & 21 & - & 31 & $1,3,5,9,10,11$ & Ciaccio (12) \\
\hline $\mathbf{F}$ & 27 & 32 & 37 & $5,9,10,11$ & Laukaitis (13) \\
\hline $\mathbf{F}$ & 23 & 25 & 42 & $5,8,9,11$ & Grinlinton (14) \\
\hline $\mathbf{F}$ & 20 & 30 & 37 & $5,9,10,11$ & Our case \\
\hline
\end{tabular}

*ACR revised criteria, 1982, for classification of $\mathrm{SLE}^{4}: 1=$ malar rash; $2=$ discoid rash; $3=$ photosensitivity; $4=$ oral ulcers; $5=$ arthritis; $6=$ serositis; $7=$ renal disorder; $8=$ neurological disorder; $9=$ haematological disorder; $10=\mathrm{im}$ munological disorder; 11 = anti-nuclear antibody.

Table II Patients with diagnosis of systemic lupus erythematosus (SLE) (fulfilling at least four of the ACR criteria) preceding myasthenia gravis (MG) development, reported since 1954

\begin{tabular}{|c|c|c|c|c|}
\hline Sex & $\begin{array}{c}\text { Age at } \\
\text { SLE onset } \\
\text { (years) }\end{array}$ & $\begin{array}{c}\text { Age at } \\
\text { MG onset } \\
\text { (years) }\end{array}$ & $\begin{array}{l}A C R \text { diagnostic } \\
\text { criteria for } S L E^{*}\end{array}$ & $\begin{array}{c}\text { Author (first) } \\
\text { (reference) }\end{array}$ \\
\hline $\mathbf{F}$ & 21 & 25 & $5,9,10,11$ & White (in 8) \\
\hline $\mathbf{F}$ & 26 & 29 & $5,6,9,10,11$ & Schoenen (in 8) \\
\hline $\mathbf{F}$ & 17 & 20 & $5,6,10,11$ & Branch (in 8) \\
\hline $\mathrm{F}$ & 30 & 30 & $3,5,7,10,11$ & Mizon (8) \\
\hline $\mathrm{F}$ & 20 & 33 & $1,3,5,6,7,10$ & Chan (15) \\
\hline $\mathbf{F}$ & 52 & 57 & $5,6,7,10,11$ & Killian (16) \\
\hline $\mathbf{F}$ & 13 & 25 & $1,2,5,8,9,10,11$ & Ciaccio (12) \\
\hline $\mathbf{F}$ & 27 & 30 & $5,9,10,11$ & Valesini (17) \\
\hline $\mathbf{F}$ & 25 & $? 25$ & $? 5,6,9,10,11$ & Thorlacius (18) \\
\hline $\mathbf{F}$ & 28 & $? 32$ & $1, ? 5,9,10,11$ & Thorlacius (18) \\
\hline $\mathbf{F}$ & 33 & $? 35$ & $? 5,8,9,10,11$ & Thorlacius (18) \\
\hline $\mathbf{F}$ & 35 & 39 & $1,5,6,9,10,11$ & Ben-Chetrit (19) \\
\hline $\mathbf{F}$ & 18 & 22 & $4,5,6,9,10,11$ & Our case \\
\hline
\end{tabular}

*See footnote in Table I. 
manifestations of SLE are equally distributed among patients of either disease onset and do not differ from those observed in SLE in general. ${ }^{19}$

Therapeutic thymectomy was performed in 10 of 14 MG patients (Table I), 1-17 years (average 5.2 years) prior to the diagnosis of SLE. The role of thymectomy in the development of SLE in these patients is not clear. The loss of thymic hormone(s) resulting in defects in suppressor cell function has been considered to be of potential importance in the pathogenesis of SLE, since these defects were partially reversed in vitro by the addition of thymic hormone(s).$^{10,20}$ However, thymectomy in lupusprone mice does not modify disease symptoms and it does not induce SLE in normal mice. ${ }^{21}$ Thymectomy has been performed in some SLE patients; no significant clinical improvement or decrease in the titres of circulating autoantibodies were noted. ${ }^{22}$ Thus, it is reasonable to speculate that thymectomy in particular was not a precipitating factor for the development of SLE in the thymectomized MG patients.

To our view, a sequence of thymic changes may result in loss of tolerance and excessive help from autoreactive $\mathrm{T}$ cells to $\mathrm{B}$ cells for (over)production of autoantibodies in all patients with the association of MG and SLE. Autoantibody-mediated events could be responsible for a common immunopathogenesis of both diseases, while molecular mimicry, one of the potential mechanisms for initiating and/or perpetuating autoantibody secre-

\section{References}

1. Shoenfeld, Y. \& Isenberg, D.A. The Mosaic of Autoimmunity. Elsevier, Amsterdam, 1989.

2. Tsokos, G.C. Overview of cellular immune function in systemic lupus erythematosus. In: Lahita, R.C. (ed.) Systemic Lupus Erythematosus, 2nd edn. Churchill-Livingstone, New York, 1992, pp. 12-48.

3. Levinson, A.I., Zweiman, B. \& Lisak, R.P. Immunopathogenesis and treatment of myasthenia gravis. J Clin Immunol 1987, 7: 187-197.

4. Tan, E.M., Cohen, A., Fries, J.F. et al. The 1982 revised criteria for the classification of systemic lupus erythematosus. Arthritis Rheum 1982, 25: 1271-1277.

5. Sfikakis, P.P., Souliotis, V.L. \& Panayotidis, P. Suppression of interleukin-2 and interleukin-2 receptor biosynthesis by gold compounds in in vitro activated human peripheral blood mononuclear cells. Arthritis Rheum 1993, 36: 208-212.

6. Alarcon-Segovia, D. Drug-induced systemic lupus erythematosus and related syndromes. Clin Rheum Dis 1975, 1: 573-587.

7. Stohl, W. Impaired generation of polyclonal T-cell mediated cytolytic activity despite normal polyclonal $\mathrm{T}$ cell proliferation in systemic lupus erythematosus. Clin Immunol Immunopathol 1992, 63: 163-172.

8. Mizon, J.P., Morcamp, D., Lefebvre, P., Froissart, M., Guidicelli, C.P. \& Goasguen, J. Associated myasthenia and disseminated lupus erythematosus. A report on two patients and complete review of the published literature. Ann Med Intern 1979, 11: 489-500.

9. Abbruzzese, G., Abbruzzese, M. Bacigalupo, A. et al. Systemic lupus erythematosus after thymectomy in a patient with myasthenia gravis. Neurology 1979, 29: 1436-1437. tion, ${ }^{23}$ may also be involved in the association of MG and SLE. Recently, a striking similarity between the sequence segment $\alpha 65-80$ of human acetylcholine receptor for the U1 small nuclear ribonucleoprotein, which is a marker autoantigen for SLE, as well as for mixed connective tissue disease has been reported.$^{24}$ Of note, most anti-Rach autoantibodies are against a small area of the acetylcholine receptor $\alpha$ subunit, called the main immunogenic region, a main loop of which is within the segment $\alpha 65-80{ }^{25}$ Thus, it is conceivable that different autoimmune diseases start with a common broad spectrum of reactivity against multiple autoantigens, and particularly in patients with MG, due to such structural similarities, the polyreactive response focuses towards the main immunogenic region of the acetylcholine receptor.

In a series of consecutive MG patients, a prevalence of SLE (although not necessarily fulfilling ACR criteria) of $8.3 \%^{18}$ and $2.2 \%{ }^{26}$ has been reported. This prevalence is clearly higher than that expected in the general population. No study has been published regarding the prevalence of MG in a pure SLE population. However, SLE patients with muscular weakness and increasing fatigue during the day, with or without neurological findings, should be referred for an EMG examination and determination of anti-R-ach antibodies in order to confirm or exclude MG.

10. Calabrese, R.H., Bach, J.F., Currie, T. et al. Development of systemic lupus erythematosus after thymectomy for myasthenia gravis. Studies of suppressor cell function. Arch Intern Med 1981, 141: 253-255.

11. Le Loet, X., Pouyol, F., Lees, O. et al. Lupus erythemateaux aigu dissemine survenu apres thymectomie pour myasthenie. Etude sequentielle des sous-populations lymphocytaires. $\operatorname{Rev}$ Med Intern 1986, 7: 425-432.

12. Ciaccio, M., Parodi, A. \& Reboza, A. Myasthenia gravis and lupus erythematosus. Int J Dermatol 1989, 28: 317-320.

13. Laukaitis, J.P. \& Borenstein, D.G. Multiple autoimmune diseases in a predisposed patient. Arthritis Rheum 1989, 32: 119-120.

14. Grinlinton, F.M., Lynch, N.M. \& Hart, H.H. A pair of monozygotic twins who are concordant for myasthenia gravis but became discordant for systemic lupus erythematosus post-thymectomy. Arthritis Rheum 1991, 34: 916 919.

15. Chan, M.K. \& Britton, M. Comparative clinical features in patients with myasthenia gravis with systemic lupus erythematosus. $J$ Rheumatol 1980, 7: 838-842.

16. Killian, P.J. \& Hoffman, G.S. Coexistence of systemic lupus erythematosus and myasthenia gravis. South Med J 1980, 73: 244-246.

17. Valesini, G., Pastore, R., De Bernandinis, P.G., Serafini, U., Vincent, A. \& Bottazzo, G.F. Appearance of antiacetylcholine receptor antibodies coincident with onset of myasthenic weakness in patient with systemic lupus erythematosus. Lancet 1983, i: 831 . 
18. Thorlacius, S., Aarli, J.A., Riise, T., Matre, R. \& Johnsen, H.J. Associated disorders in myasthenia gravis: autoimmune diseases and their relation to thymectomy. Acta Neurol Scand 1989, 80: 290-295.

19. Ben-Chetrit, E., Pollack, A., Flusser, A. \& Rubinow, A Coexistence of systemic lupus erythematosus and myasthenia gravis: two distinct populations of anti-DNA and antiacetylcholine receptor antibodies. Clin Exp Rheumatol 1990, 8: $71-74$.

20. Rothfield, N. Systemic lupus erythematosus: clinical aspects and treatment. In: McCarty, D.J. \& Koopman, W.J. (eds) Arthritis and Allied Conditions, 12th edn. Lea and Febiger, Philadelphia, 1993, p. 1155.

21. Hang, M., Theofilopoulos, A., Balderas, R., Francis, S. \& Dixon, $F$. The effect of thymectomy on lupus-prone mice. $J$ Immunol 1984, 132: 1809-1813.
22. Mackay, I.R. \& Smalley, M. Results of the thymectomy in SLE: observations on clinical course and serological reactions. Clin Exp Immunol 1966, 1: 129-138.

23. Steinberg, A.D., Krieg, A.M., Gourley, M.F. \& Klinman, D.M. Theoretical and experimental approaches to generalised autoimmunity. Immunol Rev 1990, 118: 129-163.

24. Manfredi, A.A., Bellone, M., Protti, M.P. \& Conti-Tronconi, B.M. Molecular mimicry among human autoantigens. Immunol Today 1991, 12: 46-47.

25. Tzartos, S.J., Kokla, A., Walgrave, S. \& Conti-Tronconi, B.M. Localisation of the main immunogenic region of human muscle acetylcholine receptor to residues $67-76$ of the a subunit. Proc Natl Acad Sci 1988, 85: 2899-2903.

26. Oesterhuis, H.J. Observations of the natural course of myasthenia gravis and the effect of thymectomy. Ann NY Acad Sci 1981, 377: 678-689. 